\title{
THE TECHNICAL STORY OF THE FREQUENCIES
}

\author{
ISY B. G. LAMME
}

\section{Abstract of Paper}

The various frequencies used in alternating-current work in America are first mentioned, and the primary reasons for their introduction are given. This covers, to a certain extent, the merits and demerits of each frequency as then understood, and the reasons each one met certain pressing commercial conditions at the time it was brought out. This is followed by a discussion of various alternating current applications which were more or less dependent upon frequency.

It is shown that there was an apparent need for two standard frequencies in the region of 60 and 25 cycles, and, further, why 60 and 25 cycles have prevailed. The special fields of application of each one are discussed fully and it is shown why 25 cycles tended to dominate the field.

The persistent developments of the designing engineers gradually overcame the limitations in various types of 60 -cycle apparatus so that eventually the 60 -cycle system in its application approached more and more closely to the 25 -cycle and, in the end, has taken the lead.

The outcome of the battle of the frequencies was determined far more by the conditions in the operating field than by the exploitation of any particular system by designing engineers. As a consequence, the energies of the engineers were directed exclusively toward overcoming the defects and limitations of the systems and not expended in fighting each other.

$\mathrm{T}_{\mathrm{q}}$ HE STORY of how and why the various commercial frequencies came into use and then dropped out again, in most cases, is not primarily the story of the frequencies themselves, but of the various uses to which the alternating current has been applied.* In other words, fundamental changes in the application of alternating current have led to radical changes in the frequencies. Some of the applications which have had a determining factor on the frequency of the supply system are as follows; incandescent lighting, transformers, transmission systems, arc lighting, induction motors, synchronous converters, constructional conditions in rotating machinery, and operating conditions. A brief consideration of these items individually,

\footnotetext{
Manuscript of this paper was received December 12, 1917; released for publication Dec. 15, 1917.

*It should be distinctly understood that this paper covers only the story of American development.
} 
from the present viewpoint, indicates that while some of them had, at one time, very considerable influence in determining frequency conditions, yet, in a number of cases, the original reasons have disappeared through improvements and refinements, as will be described later.

At various times the following standard frequencies have been in use in this country, namely, $1331 / 3,125,831 / 3,662 / 3$, $60,50,40,30$ and 25 cycles per second. These did not appear chronologically in the order given above, and. a few odd frequencies in a few special applications are omitted.

In the following, the various frequencies will be considered more or less in the order of their development and basic reasons will be given for their choice, and the writer will endeavor to show why certain of them have persisted, while others have dropped out. It will also be shown why the commercial situation has first tended strongly toward certain frequencies and afterwards swung toward others.

\section{AND 125 Cycles}

In the earliest alternating work, the whole service consisted of incandescent lighting, and the electric equipment was made up of small high-speed belted single-phase generators and houseto-house distributing transformers. As the transformers were of small capacity and as their design was in a very crude state, it was believed that a relatively high frequency would best meet the transformer conditions. A choice of such an odd frequency as $1331 / 3$ cycles per second, is due to the fact that in those early days (1886 to 1893) frequencies were usually designated in terms of alternations per minute. One of the earliest commercial generating units constructed by the Westinghouse company had a speed of $2000 \mathrm{rev}$. per min. and had eight poles. This presented a fairly convenient constructional arrangement for the surface-wound type of rotating armature, which was the only one recognized at that time. The speed of 2000 rev. per min., with eight poles, gave 16,000 alternations per minute, or $133 \frac{1}{3}$ cycles per second according to our present method of designation. Thus the earliest frequency in commercial use in this country was fixed, to a certain extent, by constructional reasons, although the house-to-house transformer problem apparently indicated the need for a relatively high frequency. The Thomson-Houston company adopted a standard frequency of 15,000 alternations per minute, (125 cycles) instead 
of the Westinghouse 16,000 , but the writer does not know why this difference was made. However, the two frequencies were so close together that practically they could be classified as one.

At this time, it should be borne in mind, there were no real transmission problems, no alternating-current arc lighting, no induction motors and the need for uniform rotation of the generators was not recognized. The induction motor, in its earliest stages, came in 1888 and considerable work was done on it in 1889 and 1890 , but it required polyphase supply circuits and comparatively low frequency and, therefore, it had no connection whatever with the then standard single-phase, $133 \frac{1}{3}$ and 125 cycle systems. The synchronous converter was also unheard of (one might say almost undreamed of) at that time.

\section{Cycles}

In 1889 or 1890 it was beginning to be recognized in this country that some lower frequency than 125 and $133 \frac{1}{3}$ cycles would be desirable. Also about this time direct-coupled and engine-type alternators were being considered in Europe and it was felt that such construction would eventually come into use in America. It was appreciated that in such case, $133 \frac{1}{3}$ cycles would present very considerable difficulties compared with some much lower frequency, due to the large number of poles which would be required. For instance, an alternator direct driven by an 80 -rev. per min. engine would require 200 poles to give the required frequency and such construction was looked upon as being practically prohibitive. About this time $\mathrm{Mr}$. L. B. Stillwell, then with the Westinghouse company, made a very careful study of this matter of a new frequency, in connection with the possibilities of engine type generators, and after analyzing a number of cases, it appeared that 7200 alternations per minute (60 cycles per second), was about as high as would be desirable for the various engine speeds then in sight. Transformer constructions and arc lighting were also considered in this analysis. While it. was deemed that a somewhat higher frequency might be better for transformers, yet a lower frequency than 60 cycles was considered as possibly better for engine type generators. A compromise between all the various conditions eventually led to 60 cycles as the best frequency. However, while this frequency originated about 1890 , it did not come into use suddenly, for it was impossible to introduce such a radical change in a brief time. Moreover, the direct-coupled 
or engine-type generator was slow in coming into general use and, therefore, there was not the necessity for the introduction of this low frequency in many of the equipments sold from 1890 to 1892 . However, by 1893,60 cycles became pretty firmly established and was sharing the business with the $133 \frac{1}{3}$-cycle systems. It should be borne in mind that, at this time, the adoption of this frequency was not considered as a direct means for bringing forward the polyphase induction motor, for the earlier 60 -cycle systems, like the 125 - and $133 \frac{1}{3}$-cycle, were all single-phase. Also, it was then thought that the polyphase motor would possibly require a still lower frequency and, moreover, the polyphase system was looked upon as in a class by itself, suitable only for induction motor work. At that time the introduction of polyphase generators for general service was not contemplated. This followed about two or three years later.

In 1890 the Westinghouse company, which had been developing the Tesla polyphase motor, laid aside the work, largely on account of there being no suitable general supply systems for this type of motor. The problem was again revived in 1892, in an experimental way, with a view to bringing out induction motor which might be applied on standard frequencies such as could be used in commercial supply circuits for lighting and other purposes. It should be understood that at this time such circuits were not in existence but were being contemplated. In 1893, after the polyphase motor had been further developed up to the point where it showed great commercial possibilities, the best means for getting it on the market were carefully considered. It was decided that the best way to promote the induction motor business was to create a demand for it on commercial alternatingcurrent systems. This meant that, in the first place, such systems must be created. Therefore, it was decided to undertake to fill the country with polyphase generating systems, which were primarily to be used for the usual lighting service. It was thought that, with such systems available, the time would soon come when there would be a call for induction motors. In this way experience would be obtained in the construction and operation of polyphase generators and the operating public would not be unduly handicapped in the use of such generators, compared with the older single-phase types.

An early example of this new practise was in the $2000-\mathrm{kw}$. polyphase generating units used for lighting the Chicago World's Fair in 1893 . Here the single-phase type still persisted, as each 
generator unit was made up of two similar frames placed side by side, but with their single phase armatures displaced one-half pole pitch from each other so that the combined machine delivered two single-phase currents displaced 90 degrees from each other. It was considered that each circuit could be regulated independently for lighting service, and polyphase motors could be operated from the two circuits. These generators (at that time the largest in this country) were designed in 1892 and were of 60 cycles. These, therefore, indicate the tendency at that time toward lower frequency and polyphase generation, although commercial polyphase motors were not yet on the market.

\section{CYCLES}

At the same time that 60 cycles was selected as a new standard it was recognized that at some future time there would be a place for some much lower frequency, but it was not until two years later that this began to narrow down to any particular frequency. In 1892 the first Niagara electrification, after several years consideration by eminent authorities, had centered on polyphase alternating current as the most desirable system. The engineers of the promoting company had also worked out what they considered the most suitable construction of machine. This involved 5000-h. p. units at 250 revolutions per minute. Prof. George Forbes, one of the engineers of the company had furnished the electrical designs for a machine with an external rotating field and an internal stationary armature. His design used eight poles, thus giving 2000 alterations per minute, or $16 \frac{2}{3}$ cycles per second. Quite independently of this, the Westinghouse company, in 1892, had been working on the development of synchronous converters, using belted 550-volt d-c. generators with twophase collector rings added. The tests on these machines had shown the practicability of such conversion and had even proved at this early date, that the converter copper losses were much lower than in the corresponding d-c. generators. Thus it is an interesting fact that the first evidence of this important principle was obtained from a shop test rather than by calculation. The writer, from an analysis of the tests, which were made under his immediate direction, concluded that the armature copper losses must be considerably lower than in the same machine used as a d-c. generator. He also brought the matter to the attention of $\mathrm{Mr}$. R. D. Mershon, then with the Westinghouse company, and the problem was then worked out mathematically by him 
and the writer, in two quite different ways, but with similar results, showing that the converter d:d have actually very much reduced copper losses.

As a result of this work of the Westinghouse company on the synchronous converter, it was decided that, to make such machines practicable, some suitable relatively low frequency was required. This appeared to be about 30 cycles. About this time the construction of the Niagara generators was taken up with the Westinghouse company to see whether it would construct these machines according to the designs submitted by the promoting company's engineers. These designs were gone over as carefully as the knowledge of such apparatus, at that time, permitted, and many apparent defects and difficulties were pointed out. The Westinghouse company then proposed, as a substitute, a 16-pole, 250 -rev. per min. machine (the speed being definitely fixed at 250 rev. per min.). This gave $33 \frac{1}{3}$ cycles or as near to the Westinghouse proposed 30 cycle system, as it was possible to get. Then many arguments were brought forward, pro and con, for the two machines and frequencies. Prof. Forbes' preference for $16 \frac{2}{3}$ cycles was based partly on the possibilities it presented for the construction and operation of commutator type motors, just as with direct current circuits. The Westinghouse contention was that this frequency was too low for any kind of service except possibly commutator type machines. Tests were made with incandescent lights and it was found that at $33 \frac{1}{3}$ cycles there was little or no winking of light, while at $16 \frac{2}{3}$ cycles, the winking was extremely bad. Tables were also made up, showing the limited number of speed combinations at $16 \frac{2}{3}$ cycles for induction motors, in case such should come into use. This showed how superior the $33 \frac{1}{3}$ cycles would be as regards such apparatus. It was also brought out that synchronous converters, when such became commercial, would be much better adapted for the higher frequency, as the choice of speeds would be much greater. From the present viewpoint the arguments appear to have been much in favor of the Westinghouse side of the case.

As a consequence of all this discussion the suggestion was advanced by some one, that a 12 pole, 250 -revolution machine, (that is, 3000 alternations, or 25 cycles), might meet sufficiently the good qualities of both of the proposed frequencies and would thus be a good compromise. In consequence a 12-pole, 25-cycle machine was worked up by the Westinghouse company and 
eventually this frequency was adopted for the Niagara generators. Afterwards, while these generators were being constructed it was brought out pretty strongly that the great advantage of this frequency would be in connection with synchronous converter operation, but that it was also extremely well adapted for slow-speed engine type generators, which were then coming into use. In consequence of the prominence given this frequency it was soon adopted as a standard low frequency, especially in those plants where synchronous converters were expected to form a prominent part of the system.

However, while 60 and 25 cycles came into use, as described above, it must be recognized that they had competitors. For instance, $66 \frac{2}{3}$ cycles (8000 alternations or one-half of 16,000 ) was used to a considerable extent by one of the manufacturing companies. Also 50 cycles came into use in certain plants and, to a certain extent, is still retained, but has become the standard high frequency of Europe. Instead of 25 cycles, the Westinghouse company advocated 30 cycles for some of its plants, largely because with the 25 per cent higher speeds permissible with such frequencies, the capacities of induction motors could be correspondingly increased and also incandescent lighting was more satisfactory. However, it was soon recognized that the $66 \frac{2}{3}$ and 30 cycle variations from the two leading frequencies of 60 and 25 cycles were hardly worth while, and they were gradually dropped, except in plants already installed. A brief attempt was made at a somewhat later period to place 40 cycles upon the market as a substitute for both 25 and 60 cycles. This was done under the impression that 40 cycles would give a universal system for arc and incandescent lighting, transmission, induction motors, synchronous converters and about everything else. This frequency possessed many merits and it was thought, at one time, that it might win out, but apparently the other two frequencies were too well established, and the 40 cycle system eventually lost ground.

The problem of the frequencies finally narrowed down to the two standards, and these two were accepted because it was thought that they covered such entirely different fields of service that neither of them could ever expect to cover the whole. In other words, two standards were required to cover the whole range of service. It was recognized that 25 cycles would not take care of alternating-current arc lighting and that it was questionable for incandescent lighting in general. In other ways, 
such as suitability for engine-type construction, application to induction motors and synchronous converters and transmission of power to long distances, it met the needs of an ideal system, as then understood. Also, in parallel operation of engine-type alternators, which was one of the serious problems of those days, the 25-cycle machines were unquestionably superior to the 60 cycle ones, due to the lesser displacement of the e. m. f. waves with respect to each other with a given angular variation in the engine speeds. However, although the 25 -cycle system presented so many advantages, it could not take care of the lighting business, and, therefore, could not entirely dominate the situation.

As regards 60 cycles, it was felt that this could handle the direct lighting situation in a very satisfactory manner and was possibly better suited for transformers than 25 cycles, although there were differences of opinion in this matter, especially when it came to the larger capacities. It was reasonably well adapted for induction motors in general, but not for very low speeds. In matters of transmission and in the operation of synchronous converters it was thought to be vitally defective.

From the above consideration it would appear that the 25cycle systems presented the stronger showing as a whole and, therefore, there was a decided tendency toward this frequency, except in those cases where lighting directly from the alternatingcurrent system was considered of prime importance. In those systems, such as many of the Edison companies, where lowvoltage three-wire direct current was used from synchronous converters, the tendency was almost solidly toward the 25-cycle system. In those days the central station, which had gotten itself committed to the 60 -cycle system so deeply that it could not change, was looked upon with commiseration. Sixty-cycle plants were looked upon, to a certain extent, as a necessary evil. In fact, so strong was the tendency toward 25 cycles that in many cases 25-cycle plants were installed for industrial purposes, where 60 cycles would have been better. The 25 -cycle synchronous converter development advanced by leaps and bounds and the machines were so good in their operation that it was believed that 60 -cycle converters could never be really competitive with them.

On the other hand, in those large plants, which were so "unfortunate" as to have 60 cycles installed, many apparent makeshifts were adopted to meet the various service requirements. 
In arc lighting, incandescent lighting, transformers and motors there was no need for makeshifts. However, in conversion to direct current, one of the greatest difficulties appeared. There were many who advocated motor-generators for this purpose, largely because the 60 -cycle converter was thought to be impracticable, in spite of the fact that the manufacturing companies were putting them on the market. The 60 -cycle converter at that time bore a bad name. It is now recognized that many of the faults of the early 60 -cycle synchronous converter operation were not in the converters themselves, but were, to a consider. able extent, in the associated apparatus. Low-speed enginetype, 60 -cycle generators were not always adapted for operation of synchronous converters. In fact, in numerous cases such generators would not operate in an entirely satisfactory manner in parallel with each other, and yet when it was attempted to operate synchronous converters from these same generators the unsatisfactory results were not blamed upon the generating system but upon defects of the converters themselves. Unfortunately, defects in the generating and transmission systems usually appeared in the converters as sparking and flashing, and such troubles naturally would be credited to defects in the construction of the converters themselves. In fact, in those days, 60 -cycle converters were expected to do things which now are considered as absurd. For instance, in one case in the writer's knowledge a 60-cycle synchronous converter was criticized as being a very badly designed piece of apparatus, due to serious flashing at times. Investigation developed that this converter was expected to operate on either one of two independent 60 -cycle systems with no rigid frequency relation to each other. The converter in service was thrown from one system to the other indiscriminately, and sometimes it flashed in the transfer and sometimes it did not. The machine was considered to be "no good" because it would not always stand such switching.

At one time the writer stood almost alone in his belief that the 60-cycle synchronous converter presented commercial possibilities sufficient to make it a strong future contender with the 25-cycle machine, provided proper supply conditions were furnished and certain difficulties in the proportions of the converter itself were overcome. One basis for his contention was that in some of the 60 -cycle plants, where the generator rotation was quite uniform, the converters were evidently much superior in their operation to other plants, using slow-speed engine-type 
generators with considerable periodic variations. In such plants the hunting tendency of the converters was very greatly reduced, with consequent improvement in sparking and general operation. It was early recognized that hunting was a very harmful condition, both in 60- and 25-cycle synchronous converters, but whereas it was a relatively rare condition in 25 -cycle plants it was much more common with 60 cycles. However, the operating public was not particularly concerned whether the trouble was in the generating plant or in the converters themselves, as long as such trouble existed and was not overcome. Very early in the synchronous converter development it was found that hunting would produce sparking or flashing at the commutators of the converters. However, even in those plants where there was no hunting apparent, there was difficulty at times due to flashing, especially with sudden change of load, which resulted in temporary increase in the d-c. voltage. This was a difficulty which was inherent in the converter itself and could not be blamed entirely upon the generating or transmitting conditions, for 25-cycle machines were practically free from this trouble under similar conditions of operation. Investigation developed the fact that this flashing trouble was due largely to unduly high value of the maximum volts between commutator bars. This difficulty was recognized long before it was overcome, simply because certain physical limitations in construction had to be removed. There were two ways in which the maximum volts per bar could be reduced, namely, by increasing the number of commutator bars per pole and by decreasing the ratio of the maximum volts to the average volts per bar, that is, by increasing the ratio of the pole width to the pole pitch, but both of these involved structural limitations in the allowable peripheral speeds of the commutator and the armature core. Here is where a little elementary mathematics comes in. The peripheral speed of the commutator is directly proportional to the distance between adjacent neutral points on the commutator, and the frequency. Therefore, with a given frequency the distance between the adjacent neutral points is directly proportional to the peripheral speed. Thus, a commutator speed of $4500 \mathrm{ft}$. per min. which was then considered an upper limit, the distance between adjacent neutral points on a 60-cycle converter is only $7 \frac{1}{2}$ in. $(19 . \mathrm{cm}$.) This distance is thus fixed mathematically and is independent of the number of poles or revolutions per minute, or anything else, except the peripheral 
speed and the frequency. With this distance of $7 \frac{1}{2}$ in., $(19 \mathrm{~cm}$.), about the only choice in commutator bars per pole was 36 , giving an average of $16 \frac{2}{3}$ volts per bar on a 600 -volt machine, and nearly 20 volts per bar with momentary increase of voltage to 700 , which is not uncommon in railway service.

However, it is not this average voltage which fixes the flashing conditions, but it is the maximum voltage between bars, and this is dependent upon the average voltage and upon the ratio of the pole width to the pole pitch. Here is where one of the serious difficulties came in. As mentioned above the pole pitch

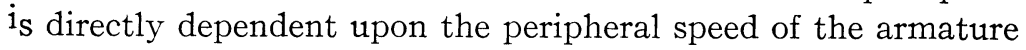
core and the frequency. Therefore, in a 60-cycle machine, if the peripheral speed is fixed, the pole pitch is at once fixed. For example, with an armature peripheral speed of $7200 \mathrm{ft}$. per. min., which was considered high at that time, the pole pitch becomes 12 in. ( $30.48 \mathrm{~cm}$.), regardless of any other considerations, and here was where a most serious difficulty was encountered. If a sufficiently wide neutral zone for commutation was allowed the interpolar space became so wide that there was not enough left for a good pole width. For instance, if the interpolar space was made 6 in. $(15.24 \mathrm{~cm}$.) wide, in order to give a sufficiently wide commutating zone to prevent sparking or flashing, due to fringing of the main field, then this left only 6 in. for the pole face. With this relatively narrow pole face the ratio of the maximum volts to the average volts was so high that with the 36 commutator bars per pole the machine was sensitive to arcing between commutator bars thus resulting in flashing. By widening the pole face this difficulty would be lessened or overcome, but with the fixed pole pitch of 12 in. $(30.48 \mathrm{~cm}$.) the neutral zone would be so narrowed as to make the machine sensitive to sparking and flashing at the brushes. Thus, no matter which way we turned we encountered trouble. Obviously there were two directions of improvement, namely, by increasing the number of commutator bars, thus reducing the average voltage, and by increasing the pole pitch, thus allowing relatively wider poles with a given interpolar space. These two conditions look simple and easy, but it took several years of experience to attain them. When we have reached apparent physical limitations in a given construction, especially when such limitations are based upon long experience, we have to feel our way quite slowly toward higher limitations. For instance, in the case of the 60 -cycle converters we could not boldly jump our 
peripheral speeds 20 to 25 per cent higher and simply assume that everything was all right. We first had to build apparatus and try it out for a year or so. Troubles, due to peripheral speed, do not always become apparent at once, and thus time tests are necessary. Therefore, while the peripheral speeds of the 60 -cycle synchronous converters were actually increased 20 to 25 per cent practically in one jump, yet it took two or three years of experimentation and endurance tests before the manufacturers felt sure enough to adopt the higher speeds on a broad commercial scale. Thus, while the change from the older more sensitive type of 60 -cycle converter to the later type occurred commercially within a comparatively short period, yet the actual development covered a much longer period.

Let us see now what an increase of 25 per cent in the peripheral speeds actually meant. As regards the commutator, the number of bars could be increased 25 per cent, that is, from 36 to 45 per pole, which was comparable with ordinary d-c. generator practise. In the second place, an increase of 25 per cent in the peripheral speed of the armature core meant a 15 -in. $(38.1-\mathrm{cm}$.) pole pitch, where 12 in. $(30.8 \mathrm{~cm}$.) was used before. Assuming, as before, a 6 -in. $(15.24-\mathrm{cm}$.) interpolar space, then the pole face itself became 9 in. $(22.8 \mathrm{~cm}$.) in width instead of 6 in. $(15.24 \mathrm{~cm}$.) or an improvement of 50 per cent. In fact, this latter improvement was so great that some manufacturers did not consider it necessary to increase the number of commutator bars, although in the Westinghouse machines both steps were made.

The above improvements so modified the 60 -cycle converter that it began to approach the 25-cycle machine in its general characteristics. It was still quite expensive compared with the 25 -cycle, due to the large number of poles, and its efficiency was considerably lower than its 25 -cycle competitor, on account of high iron and windage losses. However, due to the need for such a machine it was gradually making headway, in spite of handicaps in cost and efficiency.

Almost coincident with the initiation of the above improvements in the 60 -cycle converter, came another factor which has had much to do with the success of this type of machine. This was the advent of the turbo-generator for general service. As stated before, one of the handicaps of the 60 -cycle converter was in the non-uniform rotation of the engine type generators which were common in the period from 1897 to about 1903 or 1904 . But, about this latter date, the turbo-generator was making 
considerable inroads on the engine-type field and within a relatively short period it so superseded the former type of unit, that it was recognized as the coming standard for large alternating power service. With the turbo-generator came uniform rotation and this at once removed one of the operating difficulties of the 60-cycle converters. However, in the early days of the turbogenerator, 25 cycles still was in the lead and many of the earlier generators were made for this frequency, especially in the larger units. But it was not long before it was recognized that 60 cycles presented considerable advantage in turbo-generator design due to the higher permissible speeds. In the earlier days of turbo-generator work, this was not recognized to any extent, as the speeds of all units were so low that the effect of any speed limitations was not yet encountered. For instance, a 1500-kw., 60 -cycle turbo-generator would be made with six poles for 1200 revolutions, while a corresponding 25 cycle unit would be made with two poles for 1500 revolutions. This slightly higher speed at 25 cycles about counterbalanced the difficulties of the twopole construction compared with the six-pole. However, before long, more experience enabled the six pole, 60-cycle machine to be replaced at 1800 revolutions, and a little later by two poles at 3600 revolutions. This, of course, turned the scales very much in the other direction. In larger units, however, the advantage still appeared to be in favor of 25 cycles, but in the course of development, 1500 revolutions was adopted quite generally for 25-cycle work, and this was the limiting speed, as such machines had only two poles, or the smallest number possible with ordinary constructions. On the other hand, for 60 cycles, 1800 revolutions was adopted quite generally for units up to almost the extreme capacities that had been considered, consequently the constructional conditions in the large machines swung in favor of 60 cycles. Therefore, with the coming of the steam turbine and the development of high-speed turbo-generator units, the tendency has been strongly toward 60 cycles. This, with the greater perfection of the 60-cycle converter, had much to do with directing the practise away from the 25 cycles.

However, there were other conditions which tended strongly toward 60 cycles. In the early development of the induction motor, the 25-cycle machines were considerably better than the 60 -cycle and possibly little or no more expensive. However, as refinements in design and practise came in, certain important advantages of the 60-cycle began to crop out. For instance, 
with 25 cycles there is but little choice in speed, for small and moderate size motors. At this frequency a four-pole motor has a synchronous speed of only 750 . The only higher speed permissible is 1500 revolutions with two poles, and it so happens that in induction motors the two-pole construction is not materially cheaper than the four pole, consequently the principal advantage in going to 1500 revolutions was only in getting a higher speed where such was necessary for other reasons than first cost. However, in 60 cycles the case is quite different, where a fourpole machine can have a speed of 1800 revolutions, synchronous, a six pole 1200 , an eight pole 900 and a ten pole 720 revolutions. In other words, there are four suitable speed combinations where a 25 cycle motor had only one. Moreover, with the advance in design it developed that these higher speed 60 -cycle motors could be made with nearly as good performances as with the 25 -cycle motors of same capacity, and at somewhat less cost. However, leaving out the question of cost, the wider choice of speeds alone would be enough to give the 60 -cycle motor a pronounced preference for general service.

However, there is one exception to the above. Where very low-speed motors are required, such as 100 rev. per min., the 60 cycle induction motor is at a considerable disadvantage compared with 25 cycles, or this has been the case in the past. It is partly for this reason that the steel mill industry, through its electrical engineers, adopted 25 cycles as standard some ten or fifteen years ago. At that time, it was considered that in mill work, in general, there would be need for very low-speed motors in very many cases. However, due to first cost, as well as other things, there has been a tendency toward much higher speeds in steel mill work, through the use of gears and otherwise, so that part of this argument has been lost. However, there still remain certain classes of work where direct connected very low-speed induction motors are desirable and where 25 cycles would appear to have a distinct advantage.

In view of the above considerations, steel mill work has heretofore gone very largely toward 25 cycles, particularly where the mills installed their own power plants. However, in recent years there has been a pronounced tendency toward purchase of power, by steel mills, from central stations, and the previously described tendency of central stations toward 60 cycles has forced the situation somewhat in the steel mills, particularly in those cases where the central power supply company can furnish 
power at more reasonable rates than the steel mill can produce in its own plant. This, therefore, has meant a tendency toward 60 cycles in steel mill work, even with the handicap of inferior lowspeed induction motors. But, on the other hand, remedies have been brought forward even for this condition. The great difficulty in the construction of low-speed, 60-cycle induction motors is in the very large size and cost if constructed for normal power factors, or the very low power factor and poor performance if constructed of dimensions and costs comparable with 25 cycles. In the latter case the extra cost is not entirely eliminated because a low power factor of the primary input implies additional generating capacity, or some means for correcting power factor on the primary system. However, in some cases it is entirely practicable to correct the power factor in the motors themselves by the use of so called "phase advancers" of either the Leblanc or the Kapp type. Such phase advancers are machines connected in the secondary circuits of induction motors and so arranged as to furnish the necessary magnetizing current to the rotor or secondary instead of to the primary. In this way the primary current to the motor will represent largely energy and the power factors can be made equal to, or even much better than in, the corresponding 25-cycle motor; or, in some cases, the conditions may be carried even further so that the motor is purposely designed with a relatively poor power factor, in order to further reduce the size and cost, and the phase advancers are made correspondingly larger. In those cases where the cost of the phase advancer is relatively small compared with the main motor, there may be a considerable saving in the cost of the main motor and then adding part of the saving to the cost of the phase advancer.

One difficulty in the use of phase advancers is found in the variable speeds required in some kinds of mill work. In those cases where flywheels driven by the main motors are desirable to take up violent fluctuations in load, it is necessary to have considerable variations in the speed of the induction motor, in order to bring the stored energy of the flywheel into play. Unfortunately this variable speed in the induction motor is one of the most difficult conditions to take care of with a phase advancer, so that here is a condition where the 60-cycle motor is at a decided disadvantage.

Thus it may be seen from the above that even in the steel mill field, where the induction motor has the most extreme applications, there is quite a strong tendency toward 60 cycles, due to the purchase of power from central supply systems. 
There remains one more important element which has had something to do with the tendency toward 60 cycles, namely, the transmission problem. In the earlier days of transmission of alternating current, 25 cycles was considered very superior to 60 cycles due to the better inherent voltage regulation conditions. At one time, it was thought that 60 cycles had a very limited field for transmission work. However, a number of power companies in the far west had installed 60-cycle plants, principally for local service and with the growth of these plants came the necessity for increased distance of transmission through development of water powers. At first it was thought they were badly handicapped by the frequency, but gradually the apparent disadvantages of their systems were overcome and the distances of transmission were extended until it became apparent that they could accomplish practically the same results as with 25 cycles. Part of this result has been obtained by the use of regulating synchronous condensers. It is a curious fact that the possibility of synchronous motors used as condensers for correction of disturbances on transmission systems, has been known for about 25 years, but it is only within quite recent years that they have come into general use as a solution of the transmission problem, and largely in connection with 60 -cycle plants. In 1893 the writer applied for a patent on the use of synchronous motors as condensers for controlling the voltage at any point on a transmission system by means of leading or lagging currents in the condenser itself. A broad patent was obtained, but there was no particular use made of it until it had practically expired.

Another improvement came along which still further helped to advance 60 cycles to its present position, namely, the use of commutating poles in synchronous converters. The principal value of commutating poles in the 60 -cycle converters, has not been so much in an improvement in commutation over the older types of machines, as in allowing a very considerable reduction in the number of poles with corresponding increase in speed, resulting in reduction in dimensions. As a direct result of this increase in speed the efficiencies of the converters have been increased. If, for instance, the speed of a given 60 -cycle converter can be doubled by cutting its number of poles to one-half, while keeping the same pole pitch and the same limiting peripheral speed, then obviously the amount of iron in the armature core is practically halved and, at the same magnetic densities the iron loss is also practically halved. Also with the same 
peripheral speed and half diameter of armature the windage losses can be decreased materially. Thus the two principal losses in the older converters have been very much reduced. There have also been reductions in the total watts for field excitation, and in other parts, so that, as a whole, the efficiency for a given capacity 60 -cycle converter has been brought up quite close to that of the corresponding 25-cycle machine, even when the latter is equipped with commutating poles. This gain of the higher frequency compared with the lower is due to the fact that the lower-frequency machine was much more handicapped in its possibilities of speed increase, and furthermore, the iron losses and windage represented a much smaller proportion of the total losses in the low-frequency machine. This improvement in the efficiency of the 60-cycle converter together with the lower losses in the 60-cycle transformer as compared with the 25 -cycle, has brought the 60 -cycle equipment almost up to the 25-cycle, so that the difference at present is not of controlling importance. This development has given further impetus toward the acceptance of 60 cycles as a general system.

Formerly a serious competitor with the 60 cycle converter was the 60-cycle motor-generator. This was installed in many cases because it was considered more reliable and more flexible in operation than the synchronous converter. Both of these claims were true to a certain extent. However, with improvements in the synchronous coverter the difference in reliability practically disappeared, but there remained the difference in flexibility. In the motor-generator set, the d-c. voltage could be varied over quite a wide range, while in the older 60 -cycle rotaries the d-c. voltage held a rigid relation to the alternating supply voltage. However, with the development and perfection of the synchronous booster type of converter, flexibility in voltage was obtained with relatively small increase in cost and minor loss in economy. This has been the last big step in putting the 60 -cycle converter at the front as a conversion apparatus, so that today it stands as the cheapest and most economical method of converting alternating current to direct current. Moreover, while the 25-cycle synchronous converter has apparently reached about its upper limit in speed, there are still possibilities left for the 60 -cycle converter.

In line with the above it is of interest to note that for units of $1000 \mathrm{kw}$. and less, the 60-cycle converter has nearly driven the 25 -cycle out of business from the manufacturing standpoint. 
For the very large size converters, 25 cycles still has the call, but largely in connection with many of the railway and threewire systems, which have been installed for many years; that is, the growth of this business is in connection with existing generating systems. However, the 60 -cycle converter, in large capacity units, is gaining ground rapidly and it is of interest to note that the largest converters yet built, namely, $5800 \mathrm{kw}$., are of the 60-cycle type.

One most interesting point may be brought out in connection with the above described "battle of the frequencies", namely, it was fought out in the operating field, and between conditions of service, and not between the manufacturing companies. This is a very good example of how such matters should be handled. Here the engineers of the manufacturing companies were expending their efforts to get all possible out of both frequencies, and consequently development proceeded apace. When 60 -cycle frequency seemed to be overshadowed by its 25 -cycle competitor, the engineers took a lesson from the latter and proceeded to overcome the shortcomings of the former. It was no innate preference of the designing engineers that has brought the higher frequency to the fore; it was the recognition that it had greater merits as a general system, if its weak points could be sufficiently strengthened; and, therefore, the engineers turned their best efforts toward accomplishing this result.

It must not be assumed, for a moment even, that because 60 cycles appears to be the future frequency in this country, that 25 cycles was a mistake. Decidedly it was not. In reality it formed a most important step toward the present high development of the electric industry. Many things we are now accomplishing with 60 cycles would possibly never have been brought to present perfection, if the success of the corresponding 25 -cycle apparatus had not pointed the way. The success of the 25-cycle converter, and the high standard of operation attained, gave ground for belief that practically equal results were obtainable with 60 cycles. Therefore, the 25 -cycle frequency served a vast purpose in electrical development; it was a high class pacemaker, and it isn't entirely out-distanced yet.

There has been considerable speculation as to what two standard frequencies would have met the needs of the service in the best manner, and would have resulted in the greatest development in the end. It has been claimed by some, that 50 and 25 cycles would have been better than 60 and 25 . In the earlier 
days possibly the former would have been better, but as a result both standards might have persisted longer. In any case, the general advantages would have been small. In one class of machines, namely, frequency changers, consisting of two alternators coupled together, the 25-50 combination would certainly have been advantageous.

Again it has been questioned whether 30 and 60 cycles would not have been a better choice. This was the original Westinghouse choice of frequencies, but not on account of frequency changers. As stated before, it was felt that 30 cycles could do about all that 25 cycles could, and would give an advantage of 25 per cent higher speed in motors and converters, with correspondingly higher capacities. Also for direct coupled alternators, the two-to-one ratio of frequencies would fit in nicely with engine speeds, in most cases. Possibly, from the present viewpoint, the choice of thirty cycles, would have longer retained the double standard.

Something further may be said regarding the 40 -cycle system, brought out by the General Electric Company. This contained many very good features, for the time it was brought out. It was then believed that if the 60 cycle frequency was retained, the double standard was necessary. The 40 -cycle system was an attempt to eliminate this double standard. It apparently furnished a better solution than 60 cycles then promised for the synchronous converter problem, and was a fair compromise in about everything else. But it came too late, for the 25-cycle system was too firmly entrenched, and for further development, the designing engineers preferred to expend their energies in seeing what could be accomplished with 60 cycles, as this seemed to present greater possibilities than either 25 or 40 , if it could be sufficiently perfected. Thus the 40-cycle system probably missed success due to being just a little too late.

As to 50 cycles, it was stated that this is still in use to a limited extent. Most of the 50-cycle plants in this country are in California. Such plants were started during the nebulous period of the frequencies, and have persisted, to a certain extent, partly because certain 60 -cycle apparatus could be easily modified to meet the 50 -cycle requirements. Also, as 50 cycles is the standard in many foreign countries to which this country exports equipment, the use of 50 cycles in some home plants has not been unduly burdensome from the manufacturers' standpoint.

In addition to the preceding, there have been certain classes 
of electric service which have depended upon frequency, but which have not been a determining factor in fixing any particular frequency. Among these may be considered commutating types of a-c. apparatus. The first a-c. commutating motors of any importance, which appeared, were, of course, the 25cycle, single-phase railway motors. These as a rule have operated from their own generating plants, or from other plants through frequency-converting machinery. One exception in the railway work may be noted in the use of 15 cycles on the Visalia plant in California. There is a pretty well defined opinion among certain engineers experienced in such apparatus that some low frequency, such as 15 cycles, would present very considerable advantages in the use of single-phase railway motors in very heavy service, such as on some of the western mountain roads. Here the problem is to get the largest possible motor capacity on a given locomotive, and the main advantage of the lower frequency would be in allowing a very materially higher capacity within a given space. This does not imply reduced weight or cost compared with the 25 cycles, but simply means greater motor capacity. With the modern, more highly developed, singlephase types of railway motors, it would appear that there may be very considerable possibilities in 15 cycles.

Outside of the railway field, there has been more recently a development of various types of a-c. commutating apparatus, principally in connection with heavy steel mill electrification work. Such apparatus has been largely in the form of three phase commutating machines and these have been used principally in connection with speed control of large induction motors. As these regulating machines are usually connected in the secondary circuits of induction motors, the frequency supplied is represented by the slip frequency. Consequently where the slip frequency never rises to a large percentage of that of the primary system, such commutating motors are applicable without undue difficulties. Such motors, presumably are better adapted for 25 -cycle mill equipments than for 60 -cycle, but due to the tendency, already described, for steel mills to go to 60 cycles on purchased power, it has been necessary to build these three-phase commutating motors for the regulation of 60 -cycle main motors, in many cases.

There is still another class of service, which has come in recently, where the choice of frequency is of much importance, but where there is no great necessity for adhering to any standard, 
namely, in heavy ship propulsion by electric motors. As each ship equipment is a complete system in itself, and as it cannot tie up with other systems, there is not any controlling need for maintaining any definite frequency or voltage. Except in similar vessels, there is little chance for duplication in parts, as the various equipments vary so much in size and capacity. In consequence it has been found advisable, at least up to the present time, to design each propulsion equipment for that frequency which best suits the generator and motor speeds, taking into account the various operating conditions and limitations, such as the different running speeds, steaming radius, etc. In consequence, different maufacturers bidding on such equipments may specify different frequencies, depending upon the constructional features of their particular types of apparatus. At the present time with the relatively small amount of experience obtained with the electrical propulsion of ships, it looks as if it would be a considerable handicap to attempt to adopt some standard frequency for all service. Later, with wide experience, it may be possible to adopt some compromise frequency, which will not unduly handicap any of the service.

\section{Conclusion}

It has been the writer's intention to show that, as a rule, the choice of frequency has been a matter of most serious consideration, based upon service conditions at the time. Moreover, in view of the wide range of conditions encountered, it is surprising how few frequencies have been seriously considered in this country. Occasion has arisen, times without number, where an obvious solution of a given problem would lie in modification of the frequency to allow the use of apparatus and equipment already designed, but the engineers of the manufacturing organization have steadily held out against such policy, regardless of the apparent need of the moment. The swing of the pendulum from 60 cycles to 25 cycles and back, has covered a period of many years and, therefore, cannot be considered as a fad of the moment, but is the result of well defined tendencies, backed by the best engineering experience available. As a rule no manufacturer has made any particular frequency his "pet," but all have worked to develop each system to its utmost. 